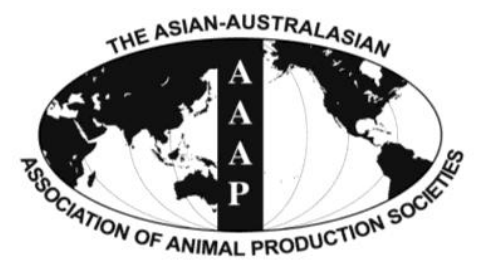

Asian-Aust. J. Anim. Sci.

Vol. 25, No. 5 : 648 - 652

May 2012

www.ajas.info

http://dx.doi.org/10.5713/ajas.2011.11386

\title{
Fatty Acid Profiles and Stearoyl-CoA Desaturase Gene Expression in Longissimus dorsi Muscle of Growing Lambs Influenced by Addition of Tea Saponins and Soybean Oil
}

\author{
H. L. Mao, J. K. Wang, J. Lin and J. X. Liu* \\ Institute of Dairy Science, Ministry of Education Key Laboratory of Molecular Animal Nutrition, \\ Zhejiang University, Hangzhou 310029, China
}

\begin{abstract}
This study was conducted to determine the effects of dietary addition of tea saponins (TS) and soybean oil (SO) on fatty acid profile and gene expression of stearoyl-CoA desaturase (SCD) in longissimus dorsi (LD) muscle of growing lambs. Thirty-two Huzhou lambs were assigned to four dietary treatments in a $2 \times 2$ factorial arrangement with main effects of TS $(0$ or $3 \mathrm{~g} / \mathrm{d})$ and SO (0 or $30 \mathrm{~g} / \mathrm{kg}$ of diet DM). The diet without additives was considered as NTNS (no TS or SO). After a feeding trial for $60 \mathrm{~d}$, four lambs of each treatment were slaughtered to collect the samples of LD muscle. Percentage of trans- 11 vaccenic acid was enhanced ( $<<0.05)$ in muscle of lambs fed TS and SO. The proportion of total conjugated linoleic acid (CLA) was increased ( $<<0.05)$ by $S O$, but decreased $(\mathrm{p}<0.05)$ by TS in LD muscle. The percentage of total saturated fatty acids in muscle was decreased ( $\mathrm{p}<0.05)$ by addition of TS and SO, while addition of SO increased $(\mathrm{p}<0.05)$ the percentage of total polyunsaturated fatty acids. The ratio of cis-9, trans-11 CLA to tran-11 vaccenic acid was decreased $(\mathrm{p}<0.05)$ by TS, but increased $(\mathrm{p}<0.05)$ by SO. The same effects were observed in SCD mRNA expression. From these results it is indicated that including TS and SO in the diet of growing lambs affect the fatty acid profiles of LD muscle and that the proportion of cis-9, trans-11 CLA in the muscle influenced by TS and SO may be related to the SCD gene expression. (Key Words: Conjugated Linoleic Acid, Lamb, Soybean Oil, Stearoyl-CoA Desaturase, Tea Saponins)
\end{abstract}

\section{INTRODUCTION}

Nutritionists have focused on increasing consumption of important polyunsaturated fatty acid (PUFA), particularly conjugated linoleic acid (CLA) that could have benefits to body composition, the immune system and atherosclerosis (MacDonald, 2000). The major CLA, cis-9, trans-11 isomer, in nature originates from ruminal biohydrogenation of dietary linoleic acid (C18:2) and linolenic acid (C18:3), as well as from endogenous synthesis from trans-11 vaccenic acid (TVA) by $\Delta^{9}$-desaturase (Santos-Silva et al., 2004). A positive linear relationship, in adipose tissue, between cis-9, trans-11 CLA and TVA levels has been reported in some studies (Madron et al., 2002; Daniel et al., 2004). Over 85\% of cis-9, trans-11 CLA in milk resulted from desaturation of TVA via the stearoyl-CoA desaturase (SCD) enzyme (Mosley et al., 2006). Thus, increasing SCD gene expression may improve the functional food attributes of

\footnotetext{
* Corresponding Author: J. X. Liu. Tel: +86-571-88982097, Fax: +86-571-88982930, E-mail: liujx@zju.edu.cn Submitted Oct. 24, 2011; Accepted Dec. 13, 2011; Revised Jan. 9, 2012
}

lamb by increasing the cis-9, trans-11CLA content of the tissue.

In our previous study, it was found that addition of tea saponins (TS) and soybean oil (SO) could reduce methane emission through affecting the rumen bacteria (Mao et al., 2010). Formation of CLA in the rumen has been mainly associated with bacterial activity (Kepler and Tove, 1967). Or-Rashid et al. (2007) suggested that protozoa in the rumen may increase the supply of CLA and other unsaturated fatty acids. Additionally, TS could reduce the population of protozoa (Mao et al., 2010). Therefore, TS may affect fatty acid composition of ruminant meat. In contrast, CLA contents in goat milk, subcutaneous adipose tissue of heifers and lambs have been shown to increase by dietary inclusion of C18:2 rich-oil seeds expression (Mir et al., 1999; Garcia et al., 2003; Kott et al., 2003). Thus the objectives of this study were to evaluate the effects of TS and SO added to the diets of growing lambs on intramuscular fatty acid profile and to analyze the relationship between cis-9, trans-11 CLA synthesis and SCD gene expression. 


\section{MATERIALS AND METHORDS}

\section{Sampling procedures}

Samples of longissimus dorsi (LD) muscle were taken from the growing lambs in the experiment of Mao et al. (2010). In their study, thirty-two Huzhou growing lambs were assigned to four dietary treatments with TS and SO as main effects, to investigate the effects of TS and SO on methane production, fermentation and microbial population in the rumen of growing lambs. The diets included: NTNS (no TS or SO), TS ( $3 \mathrm{~g} / \mathrm{d}$ ), SO ( $30 \mathrm{~g} / \mathrm{kg}$ of the DM), and TS plus SO (TS-SO). After the growth trial, half of the lambs (body weight $=19.6(\mathrm{SE}=0.58))$ from each treatment were slaughtered. The LD muscle samples were collected at between 10 and 12 ribs immediately after the animals were slaughtered. A sub-sample of LD muscle (about $10 \mathrm{~g}$ ) was stored frozen at $-20^{\circ} \mathrm{C}$ for fatty acid analysis. Another subsample of LD muscle $(5 \mathrm{~g})$ was immediately frozen in liquid nitrogen and stored at $-80^{\circ} \mathrm{C}$ for subsequent RNA extraction to determine the SCD gene expression.

\section{Parameters measurements}

Total lipids from sub-samples of LD muscle were extracted with chloroform: methanol $(2: 1, \mathrm{v} / \mathrm{v})$. The lipid extracts were methylated according to the method of Park and Goins (1994). Fatty acids methyl ester (FAME) were separated by gas chromatograph (Agilent GC6890N) equipped with a flame ionization detector using a fused silica capillary column (DB-5MS, $30 \mathrm{~m} \times 0.25 \mathrm{~mm} \times 0.25$ $\mu \mathrm{m})$. Individual FAME was identified by comparing with standards and quantified from peak areas to result in percentages of total fatty acids. Results for each fatty acid were expressed as percentage of the sum of all identified fatty acids.

Total RNA was extracted from the LD muscle samples according the TRIzol procedure (Invitrogen, Carlsbad, CA, USA), which included an initial centrifugation step to remove lipids from the extract according to the manufacturer's directions. Total RNA was synthesized to cDNA by using random hexamer primers and performed with a PrimeScript ${ }^{\mathrm{TM}}$ RT kit (Perfect Real Time; Takara, Dalian, China).

The PCR assays for enumeration of SCD were performed on an ABI 7500 Real-Time PCR System (Applied Biosystems, Foster City, USA) using the $\mathrm{SYBR}^{\circledR}$ Premix Ex Taq ${ }^{\mathrm{TM}}$ (Takara, Dalian, China). Primers for SCD (F: 5'-CGCTGGCACATCAACTTTACC-3', R: 5'-TTTC CTCTCCAGTTCTTTTCATCC-3') and glyceraldehyde-3phosphate dehydrogenase (GAPDH, F: 5'-TTGTGATGG GCGTGAACC-3', R: 5'-CCCTCCACGATGCCAAA-3') were designed based on the mRNA sequences of ovine SCD (AY292284) and GAPDH (AF030943), which were published at GenBank. Primers for each gene were designed to flank a region that contains at least one intron to ensure that no contaminating genomic DNA was amplified. They were synthesized by Invitrogen Corp. (Shanghai, China). The mRNA of GAPDH was used as an internal standard for the determination of SCD mRNA levels. Amplification condition was as follows: one cycle at $95^{\circ} \mathrm{C}$ for $1 \mathrm{~min}$ for initial denaturation, followed by 45 cycles of $95^{\circ} \mathrm{C}$ for $10 \mathrm{~s}$, $54^{\circ} \mathrm{C}$ for $10 \mathrm{~s}$ and $72^{\circ} \mathrm{C}$ for $34 \mathrm{~s}$. The melting curve analysis of amplication products was performed at the end of each PCR reaction to confirm that single PCR product was detected. Upon $1.2 \%$ agarose gel electrophoresis, all PCR products moved with one single band and showed the expected size. Amplification efficiencies for each primer pair were investigated by examining gradient dilution series of total ruminal microbial DNA template on the same plate in triplicate.

\section{Calculation and statistical analysis}

Abundance of SCD mRNA was expressed as a proportion of GAPDH mRNA according to the equation: Relative quantification of $\mathrm{SCD}=2^{-(\mathrm{Ct} \text { SCD-Ct GAPDH) }}$, where $\mathrm{Ct}$ represents threshold cycle.

Data were analyzed as a completely randomized block experiment using the GLM procedure of SAS (SAS, 1999). The experimental model was 2-way interactions and the main effect was TS and SO. The fatty acid profiles and SCD gene expression were studied by analysis of variance including the effects of TS, SO and their interaction. Multiple comparisons of means among treatments were carried out by Duncan's multiple range tests. Statistical significance was considered as $\mathrm{p} \leq 0.05$.

\section{RESULTS AND DISCUSSIONS}

\section{Fatty acid composition of LD muscle}

The results of intramuscular fat and fatty acid composition of LD muscle affected by TS and SO are presented in Table 1. The intramuscular fat level was higher for lambs fed diets with SO $(\mathrm{p}<0.05)$. The productive performance of animals was not significantly different among treatments due to the restricted feeding (Mao et al., 2010), suggesting that the additives rather than the growth rate contribute to the difference of fatty acid composition of LD muscle. The proportion of myristic (C14:0) was decreased $(p<0.05)$ by TS and SO. Kim et al. (2007) suggested that decrease in proportion of medium-chain fatty acid may be due to decreases in activity and mRNA abundances of lipogenic enzymes such as acetyl CoA and fatty acid synthesis. Soybean oil addition did not have a significant effect on the proportion of palmitic (C16:0) and stearic acid (C18:0) ( $>>0.05)$. However, Santos-Silva et al. (2004) observed that C16:0 and C18:0 decreased with 80 $\mathrm{g} / \mathrm{kg}$ of soybean oil inclusion in the diet. The difference 
Table 1. Effects of addition of tea saponins and soybean oil on fatty acid composition of the intramuscular fat in longissimus dorsi muscle of growing lambs

\begin{tabular}{|c|c|c|c|c|c|c|c|c|}
\hline & \multicolumn{4}{|c|}{ Diets $^{1}$} & \multirow{2}{*}{ SEM } & \multicolumn{3}{|c|}{ Effect } \\
\hline & NTNS & TS & $\mathrm{SO}$ & TS-SO & & $\mathrm{TS}$ & $\mathrm{SO}$ & $\mathrm{TS} \times \mathrm{SO}$ \\
\hline 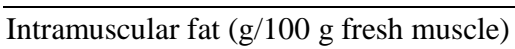 & $3.92^{\mathrm{b}}$ & $5.00^{\mathrm{b}}$ & $7.34^{\mathrm{a}}$ & $6.39^{\mathrm{a}}$ & 0.420 & ns & $* *$ & $*$ \\
\hline \multicolumn{9}{|c|}{ Fatty acid composition ( $\mathrm{g} / 100 \mathrm{~g}$ total fatty acids) } \\
\hline Myristic acid (14:0) & $3.64^{\mathrm{a}}$ & $3.52^{\mathrm{bc}}$ & $3.57^{\mathrm{ab}}$ & $3.45^{\mathrm{c}}$ & 0.029 & $* *$ & $*$ & ns \\
\hline Palmitic acid (16:0) & 24.3 & 24.2 & 24.2 & 24.1 & 0.040 & ns & ns & $\mathrm{ns}$ \\
\hline Palmitoleic acid $(16: 1)$ & $2.23^{\mathrm{b}}$ & $2.32^{\mathrm{a}}$ & $2.24^{\mathrm{b}}$ & $2.26^{\mathrm{ab}}$ & 0.027 & ns & $\mathrm{ns}$ & ns \\
\hline Stearic acid (18:0) & 16.7 & 16.6 & 16.6 & 16.7 & 0.04 & ns & ns & ns \\
\hline Oleic acid (18:1) & $36.2^{\mathrm{b}}$ & $36.3^{\mathrm{ab}}$ & $36.3^{\mathrm{ab}}$ & $36.4^{\mathrm{a}}$ & 0.06 & ns & $\mathrm{ns}$ & $\mathrm{ns}$ \\
\hline Vaccenic acid $(18: 1$, trans- 11$)$ & $1.58^{\mathrm{c}}$ & $1.70^{\mathrm{ab}}$ & $1.65^{\mathrm{b}}$ & $1.74^{\mathrm{a}}$ & 0.019 & $* * *$ & $*$ & $\mathrm{~ns}$ \\
\hline Linoleic (18:2) & 3.22 & 3.29 & 3.26 & 3.24 & 0.03 & ns & ns & ns \\
\hline Linolenic (18:3) & $0.55^{\mathrm{ab}}$ & $0.55^{\mathrm{ab}}$ & $0.58^{\mathrm{a}}$ & $0.51^{\mathrm{b}}$ & 0.017 & ns & $\mathrm{ns}$ & ns \\
\hline $\operatorname{CLA}^{2}(18: 2$, cis- 9, trans-11) & $0.54^{\mathrm{b}}$ & $0.53^{\mathrm{b}}$ & $0.61^{\mathrm{a}}$ & $0.55^{\mathrm{b}}$ & 0.009 & $* *$ & $* *$ & * \\
\hline CLA $(18: 2$, trans -10, cis-12) & $0.18^{\mathrm{ab}}$ & $0.17^{\mathrm{b}}$ & $0.18^{\mathrm{ab}}$ & $0.19^{\mathrm{a}}$ & 0.005 & ns & $*$ & $*$ \\
\hline Arachidonic acid (20:4) & 0.71 & 0.74 & 0.74 & 0.75 & 0.01 & ns & $\mathrm{ns}$ & ns \\
\hline Eicosapentaenoic acid (20:5) & 3.12 & 3.11 & 3.14 & 3.11 & 0.015 & $\mathrm{~ns}$ & $\mathrm{~ns}$ & $\mathrm{~ns}$ \\
\hline Docosapentaenoic acid (22:5) & $0.96^{\mathrm{bc}}$ & $0.93^{\mathrm{c}}$ & $1.00^{\mathrm{ab}}$ & $1.03^{\mathrm{a}}$ & 0.02 & ns & $* *$ & $\mathrm{~ns}$ \\
\hline Docosahexaenoic acid (22:6) & 0.99 & 1.02 & 1.01 & 1.04 & 0.016 & ns & $\mathrm{ns}$ & ns \\
\hline Others & $5.20^{\mathrm{a}}$ & $5.03^{\mathrm{ab}}$ & $5.02^{\mathrm{ab}}$ & $4.96^{\mathrm{b}}$ & 0.053 & $*$ & $*$ & $\mathrm{~ns}$ \\
\hline CLA & $0.73^{\mathrm{b}}$ & $0.69^{c}$ & $0.78^{\mathrm{a}}$ & $0.74^{\mathrm{b}}$ & 0.010 & $* *$ & $* * *$ & $\mathrm{~ns}$ \\
\hline $\mathrm{SFA}^{3}$ & $44.5^{\mathrm{a}}$ & $44.3^{b}$ & $44.3^{\mathrm{b}}$ & $44.3^{\mathrm{b}}$ & 0.05 & $*$ & $*$ & $\mathrm{~ns}$ \\
\hline MUFA $^{4}$ & $40.0^{\mathrm{b}}$ & $40.3^{\mathrm{a}}$ & $40.1^{\mathrm{b}}$ & $40.3^{\mathrm{a}}$ & 0.055 & $* * *$ & ns & ns \\
\hline PUFA $^{5}$ & $10.3^{\mathrm{b}}$ & $10.3^{\mathrm{b}}$ & $10.5^{\mathrm{a}}$ & $10.4^{\mathrm{ab}}$ & 0.05 & ns & $* *$ & ns \\
\hline cis-9, trans-11 CLA/vaccenic acid & $0.34^{\mathrm{b}}$ & $0.31^{\mathrm{c}}$ & $0.37^{\mathrm{a}}$ & $0.31^{\mathrm{c}}$ & 0.007 & $* * *$ & * & $\mathrm{ns}$ \\
\hline
\end{tabular}

${ }^{1}$ Diets: NTNS = No tea saponins or soybean oil; TS = Tea saponins; $\mathrm{SO}=$ Soybean oil; TS-SO = Tea saponins plus soybean oil.

${ }^{2} \mathrm{CLA}=$ Conjugated linoleic acid. ${ }^{3} \mathrm{SFA}=$ Saturated fatty acid (sum of C14:0, C16:0 and C18:0).

${ }^{4}$ MUFA = Monounsaturated fatty acid (sum of C16:1, C18:1 and trans-11 C18:1).

${ }^{5}$ PUFA = Polyunsaturated fatty acid (sum of C18:2, C18:3, cis-9, trans-11 C18:2, trans-10, cis-12 C18:2, C20:4, C20:5, C22:5 and C22:6).

$* \mathrm{p}<0.05 ; * * \mathrm{p}<0.01 ; * * * \mathrm{p}<0.001 ; \mathrm{ns}=$ Not significant.

between the two results may be due to the level of dietary oil and basal diet used.

The decrease in saturated fatty acid (SFA) was also probably due to the fact that the increase in the availability of exogenous fatty acids inhibits the de novo synthesis of fatty acids (Santos-Silva et al., 2004). The proportions of monounsaturated fatty acid (MUFA), C16:1 and C18:1, in the LD muscle was not affected ( $p>0.05)$ by oil addition. This was similar to results in sheep fed a diet containing 60 $\mathrm{g} / \mathrm{kg}$ DM of sunflower seed oil (Ivan et al., 2001), but in contrast to the finding that when lambs were fed linseed or linseed plus fish oil increases in C18:1 were observed in muscle (Rule and Smith, 1995). However, a decrease in C18:1 in muscle, adipose and liver was observed in lambs fed $60 \mathrm{~g}$ of safflower oil/kg DM (Mir et al., 2000). These observations suggested that the impact of dietary oil addition on MUFA was dependent on the type of oil addition.

The TVA was increased when either TS or SO were added to the diets $(\mathrm{p}<0.05)$. The proportion of cis-9, trans11 CLA was increased $(\mathrm{p}<0.05)$ by SO, but decreased by TS $(\mathrm{p}<0.05)$. A negative $\mathrm{TS} \times \mathrm{SO}$ interaction was also observed $(\mathrm{p}<0.05)$. Total CLA was decreased by TS, but increased by SO $(p<0.05)$. One explanation for the decrease in CLA by TS may be that the TS reduced the population of protozoa (Mao et al., 2010). Protozoa contain a greater proportion of unsaturated fatty acids and CLA than the bacteria. The presence of protozoa in the rumen could increase the supply of CLA and other unsaturated fatty acids for lower gut absorption by ruminants (Or-Rashid et al., 2007). However, Yáñez-Ruiz et al. (2007) reported that protozoa-free lambs had higher proportion of cis-9, trans-11 CLA in their tail muscle. The differences between these results may be due to the tissues sampled. Trans- 11 vaccenic acid and CLA are intermediates formed during ruminal biohydrogenation of dietary linoleic acid (Pavan et al., 2007). Some researchers reported that unsaturated fatty acid and CLA in muscle of lambs were increased by supplementation of soybean oil or safflower oil (Mir et al., 2000; Santos-Silva et al., 2004; Boles et al., 2005), while Hristov et al. (2005) did not observe changes in TVA or cis-9, trans-11 CLA when cattle were supplemented with $50 \mathrm{~g} / \mathrm{kg}$ DM of safflower oil in a 


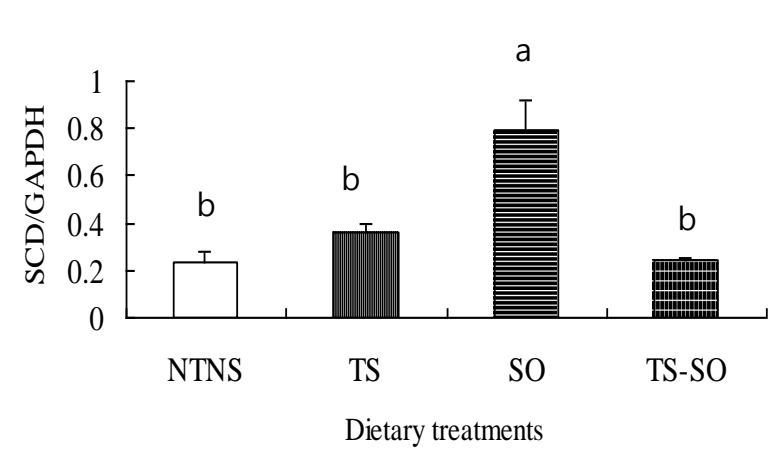

(A)

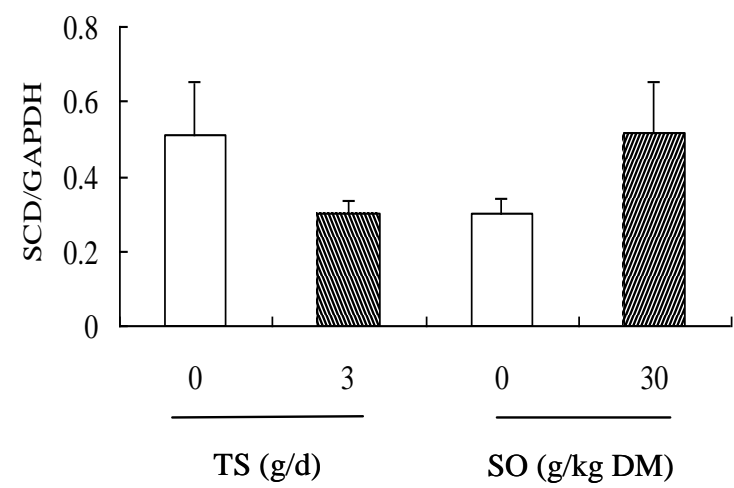

(B)

Figure 1. The mRNA abundance of stearoyl-CoA desaturase (SCD) relative to glyceraldehyde-3-phosphate dehydrogenase (GAPDH) in longissimus dorsi muscle from growing lambs with different additives: no tea saponins or soybean oil (NTNS), tea saponins (TS, $3 \mathrm{~g} / \mathrm{kg}$ $\mathrm{DM}$ ), soybean oil (SO, $30 \mathrm{~g} / \mathrm{kg} \mathrm{DM}$ ), and tea saponins plus soybean oil (TS-SO). (A) Multiple comparisons of means among treatments analyzed by Duncan's multiple range tests. ${ }^{\text {a,b }}$ Means with different letter differ significantly $(\mathrm{p}<0.05)$. (B) Results by analysis of variance including the effects of TS, SO and their interaction; $P_{\mathrm{TS}}=0.019, P_{\mathrm{SO}}=0.016, P_{\mathrm{TS} \times \mathrm{SO}}=0.002$.

finishing diet. Madron et al. (2002) observed no change in TVA or cis-9, trans-11 CLA proportion of LD muscle when extruded full-fat soybeans was supplemented to the diet of cattle at $127 \mathrm{~g} / \mathrm{kg}$ of diet DM. However, when extruded fullfat soybean was increased to $256 \mathrm{~g} / \mathrm{kg}$ of diet DM, TVA and cis-9, trans-11 CLA proportion increased in LD muscle. In the current study, $30 \mathrm{~g} / \mathrm{kg}$ DM of soybean oil addition to the diet of growing lambs increased TVA and cis-9, trans-11 CLA by 3 and 7 percentages, respectively.

The TS and SO treatments did not affect the proportion of eicosapentaenoic acid (C20:5) and docosahexaenoic acid (C22:6) in intramuscular fat. These fatty acids are synthesized by the elongation and desaturation of linolenic acid (Wood et al., 1999), the proportion of which was not affected by TS or SO in this study. The proportion of docasapentaenoic (C22:5) was increased by SO addition, consistent with the result of Santos-Silva et al. (2004).

\section{Stearoyl-CoA desaturase gene expression}

Addition of TS was associated with substantial reduction $(p<0.05$; Figure 1$)$ in the quantity of SCD mRNA relative to GAPDH. In contrast, the SO-contained diets significantly increased $(\mathrm{p}<0.05)$ the $\mathrm{SCD}$ gene expression. A TS $\times$ SO interaction was observed $(\mathrm{p}<0.05)$. Stearoyl-CoA desaturase is known as the $\Delta^{9}$ desaturase that catalyzes the biosynthesis of MUFA by introducing the first cis double bond in the $\Delta^{9}$ position (between carbons 9 and 10) (Ntambi et al., 2004). Trans- 11 vaccenic acid is a substrate for SCD, and can be converted to cis-9, trans-11 CLA by endogenous SCD. A significant linear relationship existed between TVA and cis-9, trans-11 CLA (Zheng et al., 2005; Ye et al., 2010). Peterson et al. (2002) suggested the variation in milk cis-9, trans-11 CLA levels were related to both ruminal biohydrogenation and SCD activity in the mammary gland.
Pavan et al. (2007) did not observe the negative effect on the SCD activity or expression in subcutaneous adipose tissues when steers were fed a diet with corn oil. Work in rodents has shown that diets rich in PUFA reduced hepatic abundance of SCD (Ntambi, 1999). Results from this study indicate that SCD expression in muscle was increased with SO addition, but decreased by TS. This was also confirmed indirectly from the ratio of cis-9, trans-11 CLA to TVA, which was increased by addition of SO, but decreased by TS $(\mathrm{p}<0.05$; Table 1$)$.

\section{CONCLUSIONS}

The intramuscular fat of lambs fed a diet containing TS had lower proportion of cis-9 trans-11 CLA. Dietary addition of linoleic acid-rich soybean oil was effective in decreasing SFA proportion and increasing the proportion of PUFA and CLA in the LD muscle, which is a desirable change in meat and beneficial for human health. It is inferred that the cis-9 trans-11 CLA synthesis may be mediated through the expression of SCD gene.

\section{ACKNOWLEDGEMENTS}

This study was financially supported by grants from the National Key Technology R \& D Program, China (2006BAD14B07-3).

\section{REFERENCES}

Boles, J. A., R. W. Kott, P. G. Hatfield, J. W. Bergman and C. R. Flynn. 2005. Supplemental safflower oil affects the fatty acid profile, including conjugated linoleic acid, of lamb. J. Anim. Sci. 83:2175-2181.

Daniel, Z. C. T. R., R. J. Wynn, A. M. Salter and P. J. Buttery. 
2004. Differing effects of forage and concentrate diets on the oleic acid and conjugated linoleic acid content of sheep tissues: The role of stearoyl-CoA desaturase. J. Anim. Sci. 82: 747-758.

Garcia, M. R., M. Amstalden, C. D. Morrison, D. H. Keisler and G. L. Williams. 2003. Age at puberty, total fat and conjugated linoleic acid content of carcass, and circulating metabolic hormones in beef heifers fed a diet high in linoleic acid beginning at four months of age. J. Anim. Sci. 81:261-268.

Hristov, A. N., L. R. Kennington, M. A. McGuire and C. W. Hunt. 2005. Effect of diets containing linoleic acid- or oleic acid-rich oils on ruminal fermentation and nutrient digestibility, and performance and fatty acid composition of adipose and muscle tissues of finishing cattle. J. Anim. Sci. 83:1312-1321.

Ivan, M., P. S. Mir, K. M. Koenig, L. M. Rode, L. Neill, T. Entz and Z. Mir. 2001. Effects of dietary sunflower seed oil on rumen protozoa population and tissue concentration of conjugated linoleic acid in sheep. Small Rumin. Res. 41:215227.

Kepler, C. R. and S. B. Tove. 1967. Biohydrogenation of unsaturated fatty acids. J. Biol. Chem. 242:5686-5692.

Kim, S. C., A. T. Adesogan, L. Badinga and C. R. Staples. 2007. Effects of dietary n-6:n-3 fatty acid ratio on feed intake, digestibility, and fatty acid profiles of ruminal contents, liver, and muscle of growing lambs. J. Anim. Sci. 85:706-716.

Kott, R. W., P. G. Hatfield, J. W. Bergman, C. R. Flynn, H. Van Wagoner and J. A. Boles. 2003. Feedlot performance, carcass composition, and muscle and fat CLA concentrations of lambs fed diets supplemented with safflower seeds. Small Rumin. Res. 49:11-17.

MacDonald, H. B. 2000. Conjugated linoleic acid and disease prevention: A review of current knowledge. J. Am. Coll. Nutr. 19:111S-1118S.

Madron, M. S., D. G. Peterson, D. A. Dwyer, B. A. Corl, L. H. Baumguard, D. H. Beerman and D. E. Bauman. 2002. Effect of extruded full-fat soybeans on conjugated linoleic acid content of intramuscular, intermuscular, and subcutaneous fat in beef steers. J. Anim. Sci. 80:1135-1143.

Mao, H. L., J. K. Wang, Y. Y. Zhou and J. X. Liu. 2010. Effect of addition of tea saponins and soybean oil on methane production, fermentation and microbial population in the rumen of growing lambs. Livest. Sci. 129:56-62.

Mir, Z., L. A. Goonewardene, E. Okine, S. Jaegar and H. D. Scheer. 1999. Effect of feeding canola oil on constituents, conjugated linoleic acid (CLA) and long chain fatty acids in goat milk. Small Rumin. Res. 33:137-143.

Mir, Z., M. L. Rushfeldt, P. S. Mir, L. J. Paterson and R. J. Weselake. 2000. Effect of dietary supplementation with either conjugated linoleic acid (CLA) or linoleic acid rich oil on the CLA content of lamb tissues. Small Rumin. Res. 36:25-31.
Mosley, E. E., B. Shafii, P. J. Moate and M. A. McGuire. 2006. Cis-9, trans-11 conjugated linoleic acid is synthesized directly from vaccenic acid in lactating dairy cattle. J. Nutr. 136:570575.

Ntambi, J. M. 1999. Regulation of stearoyl-CoA desaturases (SCD) by polyunsaturated fatty acids and cholesterol. J. Food Sci. 59:1262-1266.

Ntambi, J. M. and M. Miyazaki. 2004. Regulation of stearoyl-CoA desaturases and role in metabolism. Prog. Lipid Res. 43:91104.

Or-Rashid, M. M., N. E. Odongo and B. W. McBride. 2007. Fatty acid composition of ruminal bacteria and protozoa, with emphasis on conjugated linoleic acid, vaccenic acid, and oddchain and branched-chain fatty acids. J. Anim. Sci. 85:12281234.

Park, P. W. and R. E. Goins. 1994. In situ preparation of fatty acid methyl esters for analysis of fatty acid composition in food. J. Food Sci. 59:1262-1266.

Pavan, E. and S. K. Duckett. 2007. Corn oil supplementation to steers grazing endophyte-free tall fescue. II. Effects on longissimus muscle and subcutaneous adipose fatty acid composition and stearoyl-CoA desaturase activity and expression. J. Anim. Sci. 85:1731-1740.

Peterson, D. G., J. A. Kelsey and D. E. Bauman. 2002. Analysis of variation in cis-9, trans-11 conjugated linoleic acid (CLA) in milk fat of dairy cows. J. Dairy Sci. 85:2164-2172.

Rule, D. C. and S. B. Smith. 1995. Fatty acid composition of muscle and adipose tissue of meat animals. In: The Biology of Fat in Meat Animals, Current Advances (Ed. S. B. Smith and D. R. Smith). Am. Soc. Anim. Sci., Champaign, IL, USA, pp. 144-165.

Santos-Silva, J., I. A. Mendes, P. V. Portugal and R. J. B. Bessa. 2004. Effect of particle size and soybean oil supplementation on growth performance, carcass and meat quality and fatty acid composition of intramuscular lipids of lambs. Livest. Prod. Sci. 90:79-88.

SAS, Version 8.0. 1999. SAS Inst Inc, Cary, NC, USA.

Wood, J. D., M. Enster, A. V. Fisher, G. R. Nute, R. I. Richardson and P. R. Shear. 1999. Manipulating meat quality and composition. Proc. Nutr. Soc. 58:363-370.

Yáñez-Ruiz, D. R., S. Williams and C. J. Newbold. 2007. The effect of absence of protozoa on rumen biohydrogenation and the fatty acid composition of lamb muscle. Br. J. Nutr. 97:938.

Ye, J., C. Wang, H. F. Wang, H. Y. Liu, Y. M. Wang, B. Chen and J. X. Liu. 2010. Effects of palletizing and supplementary methionine, lysine and choline on the performance of periparturient dairy cows. Acta Agric. Scand. A Anim. Sci. 60: 230-238.

Zheng, H. C., J. X. Liu, J. H. Yao, Q. Yuan, H. W. Ye, J. A. Ye and Y. M. Wu. 2005. Effects of dietary sources of vegetable oils on performance of high-yielding lactating cows and conjugated linoleic acids in milk. J. Dairy Sci. 88:2037-2042. 